\title{
A fish's-eye-view: accessible tools to document shellfish farms as marine habitat in New Jersey, USA
}

\author{
Jenny P. Shinn ${ }^{1, *}$, Daphne M. Munroe ${ }^{1}$, Julie M. Rose ${ }^{2}$ \\ ${ }^{1}$ Haskin Shellfish Research Laboratory, Rutgers University, 6959 Miller Ave., Port Norris, NJ 08349, USA \\ ${ }^{2}$ NOAA Fisheries, Northeast Fisheries Science Center, Milford Laboratory, 212 Rogers Avenue, Milford, CT 06460, USA
}

\begin{abstract}
Shellfish growers routinely observe fish and invertebrates interacting with their aquaculture gear. To quantitatively assess these interactions, underwater action cameras (GoPro ${ }^{\circledR}$ ) were used to document fish and invertebrate activity in and around floating oyster bags, cages, and a natural marsh habitat on an oyster farm in the Little Egg Harbor region of Barnegat Bay, New Jersey, USA, in 2018. A free and open-source event-logging software was used to analyze video files. A total of 21 species from 4 phyla were identified across all days and sites. Nekton were quantified from continuously recorded video using the MaxN abundance metric, defined as the maximum number of individuals of a given species present within each 1 min segment of video. Species of both ecological and economic importance in the local ecosystem used the 3 intertidal habitats. Abundance and community composition observed around oyster cages differed from that around floating oyster bags and marsh edge; the latter 2 habitats were not significantly different. Juvenile fish were frequently observed, suggesting that the oyster farm may provide similar natural history functions as other natural marsh habitat.
\end{abstract}

KEY WORDS: Oyster aquaculture $\cdot$ Fish habitat $\cdot$ Ecosystem service $\cdot$ Video-based observation research · BORIS

\section{INTRODUCTION}

Complex structure in marine ecosystems provides habitat heterogeneity and increased surface area for organisms (e.g. Soniat et al. 2004). Shellfish farming may provide such a complex structure to the surrounding environment. Oyster farming makes up one-third of all shellfish production worldwide (Wijsman et al. 2019) and constitutes the largest portion of US shellfish aquaculture operations both in terms of revenue and production (NMFS 2020). The US shellfish aquaculture industry has experienced rapid growth in the last decade, and both regulators and coastal communities are interested in environmental benefits that may be provided by aquaculture gear. Off-bottom oyster cages and floating gear are an

\footnotetext{
*Corresponding author: jenny.shinn@rutgers.edu
}

increasingly common method for culturing large numbers of oysters on a small footprint. We define off-bottom farms as those that use gear in which oysters are elevated off the sea floor, including operations where the gear itself sits on the bottom. These farm gears provide complex structure for fish and invertebrates, potentially providing habitat comparable to naturally existing structured habitats, like intertidal marsh edges or seagrass beds.

Previous studies in the USA have examined the community assemblages associated with oyster farms. It is well established that aquaculture gear alters habitat (e.g. increases structural complexity) and the benthic community of the habitat in which the gear is placed. O'Beirn et al. (2004) documented 45 species of macrofauna utilizing floating oyster

๑ T The authors 2021. Open Access under Creative Commons by Attribution Licence. Use, distribution and reproduction are unrestricted. Authors and original publication must be credited. 
aquaculture gear in Virginia. Their findings highlight the diverse and abundant natural communities associated with cultured oysters, both on taxonomic and trophic levels. In Rhode Island, DeAlteris et al. (2004) concluded that oyster farm gear has substantially greater habitat value than does nonvegetated seafloor, and has ecological value equal to and possibly greater than that of submerged aquatic vegetation, another type of naturally structured, ecologically important estuarine habitat. Marenghi et al. (2010) observed that 2 types of oyster aquaculture gear (rack and bag, and floating cages) supported similar assemblages of finfish and invertebrates as restored oyster reefs in the Delaware Inland Bays.

Given the logistical differences often required to sample structured and unstructured habitats, and different biological communities that naturally reside in these habitat types, many previous studies examining fish habitat use at oyster farms were unable to use a uniform sampling method on farms and natural features (e.g. DeAlteris et al. 2004, Erbland \& Ozbay 2008). However, Glenn (2016) used a custom volumetric sampling device to sample 3 natural habitats and a replicated farm using $1 / 4$ scale farm gear in Great Bay, New Hampshire. Previous studies have also largely employed sampling methods that are known to disturb assemblages and habitats (e.g. lift nets, fish traps, suction dredge). Underwater video has been successfully used to monitor structureoriented reef species in natural habitats that are not easily sampled by traditional methods (Willis \& Babcock 2000). The use of cameras in aquaculture settings has only recently been employed on bottom cages in coastal Connecticut (Mercaldo-Allen et al. 2021) and on-bottom and long-line oyster farms in
Washington (Muething et al. 2020). In this proof-ofconcept study, we similarly used this easily adopted video recording technology to allow uniform data collection across 2 habitats created by oyster farms and 1 natural structured habitat in an estuary where this farmed habitat is representative of such and expanding future footprints.

\section{MATERIALS AND METHODS}

All data were collected at an actively farmed eastern oyster Crassostrea virginica aquaculture site in the southern Barnegat Bay, at Rose Cove, New Jersey, USA (39³6' 12.0" N, 74 18' 09.4" W). The farm is located in a shallow Atlantic Coast backbay estuary with both a long history of shellfisheries (Ford 1997) and a growing farming sector, with 20 new shellfish farm leases created in 2017.

Video data were collected using action cameras (GoPro Hero3 ${ }^{+\circledR}$ ) deployed in waterproof cases on an oyster farm and an adjacent natural structured habitat, a marsh edge. The 0.81 ha, shallow-water farm (0.5 m depth) was located on a sandy-bottom lease flanked by marsh and used 2 gear types: highdensity polyethylene (HDPE) mesh floating bags and coated metal wire bottom cages (Fig. 1). During the course of this study, the farm site contained approximately 100 floating bags and 15 oyster cages. Each cage measured $1.5 \mathrm{~m}$ (length) $\times 0.9 \mathrm{~m}$ (width) $\times$ $0.76 \mathrm{~m}$ (height) and held 12 HDPE mesh bags of oysters. Farm work (i.e. human farm-tending activity and occasional boat traffic) was ongoing during all video collections. Camera deployments collected $\sim 80$ min of continuous footage and included all tidal

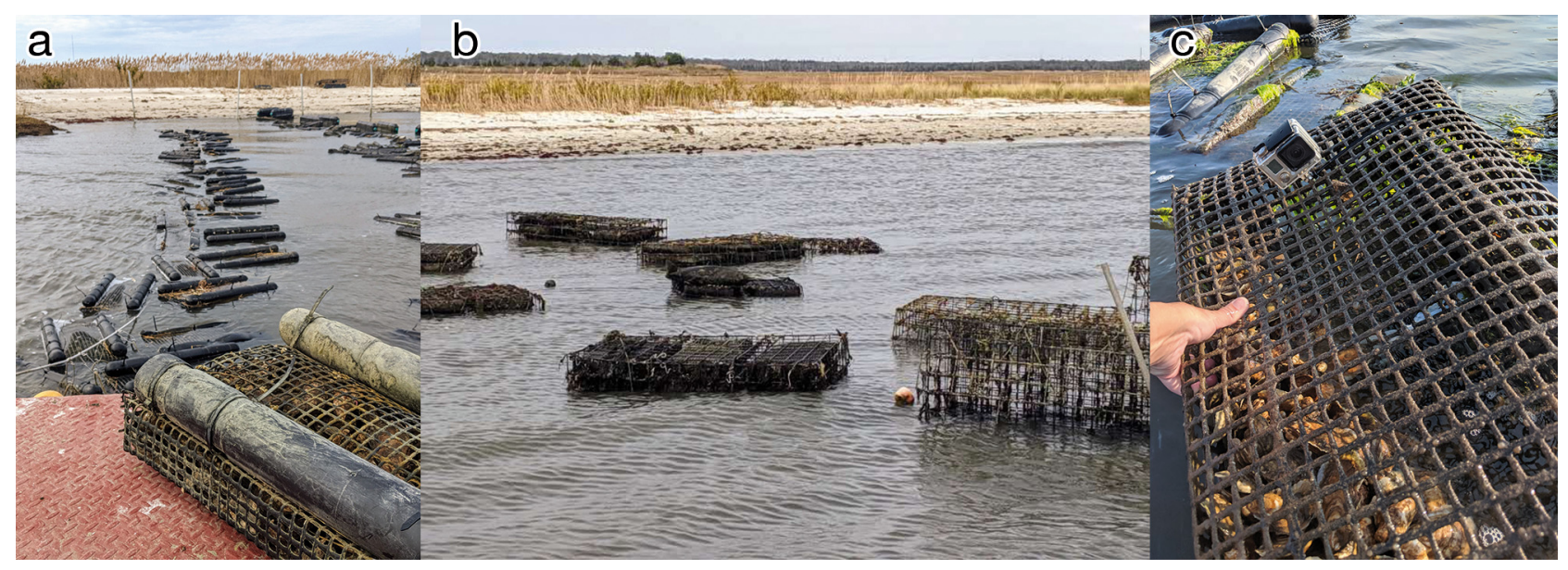

Fig. 1. (A) Floating oyster bags anchored to the bottom of the farm lease. (B) Oyster cages with grow-out bags inside viewed at low tide. (C) Video camera affixed to the bottom of a floating bag 
conditions during active farm operations on $7 \mathrm{~d}$ during July through September 2018 (8 and 28 July; 4, 12, and 25 August; 3 and 30 September). More than 7 dates were sampled, but due to various mechanical or environmental factors, some could not be analyzed and thus are not included. For each of the 7 deployments, 1 camera was set to record in each of the 3 habitat types concurrently (floating bag, cage, and marsh). A camera was attached to the bottom of a floating bag such that the bottom edge of the bag was in the water, and water directly beneath the bag was in view (Fig. 1C). A camera attached to a cage was either affixed to the top or side, such that the cage was partially in the frame and water around the cage was viewed. The adjacent marsh edge was recorded by attaching a camera to a small T-shaped platform anchored into the sediment to elevate the camera above the bottom. The marsh edge was vegetated with Spartina spp., colonized by ribbed mussels Geukensia demissa, and located about $25 \mathrm{~m}$ away from the nearest farm gear. The specific location of camera placement within the 3 treatments was randomized on each deployment. The typical camera perspective can be viewed in Video 1 at www.int-res.com/articles/suppl/q013p295_supp/

Videos were analyzed using the Behavioral Observation Research Interactive Software (BORIS; Friard \& Gamba 2016). All mobile animals (excluding some macroinvertebrate taxa) present in each video were identified to the closest possible taxon and coded in BORIS. See Video 1 for examples of species interacting with the sampled habitats.

Nekton abundance was determined using MaxN, defined as the maximum number of individuals of a given species present in a single frame within each 1 min segment of video (Campbell et al. 2015). MaxN avoids the potential for double-counting individual fish or invertebrates that repeatedly move in and out of the camera view. Because the entire structure could not be observed at once, it provides a conservative estimate of total nekton abundance. As an indicator of habitat preference, species were classified into 3 groups: those primarily using oyster reefs as habitat (obligate residents), those normally found on reefs (facultative residents), and those that range farther and tend to forage on or near reefs (transient residents) (Breitburg 1998, Coen et al. 1999).

Summary metrics were calculated for each habitat and sampling event, including total number of individuals (sum of MaxN across all species), species richness (total number of species observed), and Shannon diversity index. The community metrics were compared among habitat types using a repeated measures test based on difference scores, trimmed means, and a percentile bootstrap method. Bootstrapping was chosen over the classical repeated measures ANOVA, because bootstrapping requires no assumptions of normality or homoscedasticity and typically has higher power to detect differences between groups (Wilcox 2017). Repeated measures analysis was conducted using R v.3.6.1 (www.r-project.org).

Cumulative species richness was calculated by summing the number of species observed across all sampling dates within each habitat type. Eastern mud snails Tritia obsoleta and ctenophores (Mnemiopsis leidyi) were observed, but were removed from further analysis, as their behaviors do not exhibit strong habitat selection. Rarefaction curves were generated by plotting the cumulative number of species observed against a cumulative measure of sampling effort to test whether habitats were sampled sufficiently to represent true diversity (Holthe 1975). Rarefaction curves were plotted along with cumulative species counts over time for all 3 habitat types.

Multivariate analysis of combined fish and invertebrate data (MaxN of each species for each $80 \mathrm{~min}$ video over 3 habitat types on 7 deployment dates, $\mathrm{n}=$ 21) was performed using Primer v.7 (www.primer-e. com). A square root transformation was applied to upweight the relative contribution of the less numerically dominant species and ensure the results were not driven solely by the most abundant species. A Bray-Curtis coefficient was used to generate a similarity matrix across all pairs of samples. Non-metric multidimensional scaling (nMDS) was used to visualize relative similarities among all pairs of samples. Categorical variables such as sample month and sample habitat type were overlaid onto the nMDS plot to visualize potential patterns in habitat and time, and the ANOSIM test in Primer was used to test for differences in communities across habitat type and by month (individual dates were thus pooled to achieve a larger sample size).

\section{RESULTS}

In total, 8937 observations of animals were coded from the videos captured concurrently on the 3 habitat types over 7 sampling dates. Twenty-one species from 4 phyla (Chordata, Arthropoda, Mollusca, and Ctenophora) were observed across all days and habitats. Obligate, resident, and transient species of commercial and recreational importance were observed (Table 1), and oyster-reef-associated species were observed using all 3 habitat types. 
Significantly more total individuals were observed in the cage habitat than around the floating bags ( $\mathrm{p}=$ 0.01 ) or at the marsh edge over the 7 -date time series ( $p<0.001$; Fig. 2A). No significant differences were observed between the total number of individuals near the floating bags or marsh over time $(p=0.755)$. Likewise, no significant differences in species richness or Shannon diversity were observed among habitats for any of the pairwise combinations over time (all $p>0.05$; Fig. 2B,C). Cumulative species richness for floating bags, cages, and marsh were 14, 15, and 11, respectively. Although similar values were observed in each habitat, rarefaction curves indicated that the true richness of sampled habitats was likely higher than what was documented over the course of this study, since the number of species observed continued to increase over the study period (Fig. S1 in Supplement 1 at www.int-res.com/articles/ suppl/q013p295_suppl/).

In multidimensional space, samples tended to group more strongly by habitat type than by sample month (Fig. 3), and communities associated with the cage habitat differed significantly from the other 2 habitat types (global test, $\mathrm{p}=0.005, \mathrm{R}=0.223$; cage vs. floating bag, $\mathrm{p}=0.004, \mathrm{R}=0.378$; cage vs. marsh, $\mathrm{p}=0.027, \mathrm{R}=0.205)$. Floating bag and marsh communities were not significantly different from each other $(\mathrm{p}=0.214, \mathrm{R}=0.075)$. No significant differences were observed in community composition by month (all $\mathrm{p}>0.05$ ). Species of both eco- logical and economic importance, such as striped bass Morone saxatilis, summer flounder Paralichthys dentatus, and blue crabs Calinectes sapidus were observed using the farm gear as habitat (Table 1; Fig. S2).

\section{DISCUSSION}

Several species observed in this study were only associated with aquaculture habitats, suggesting that the oyster farm gear may provide a habitat element not found on adjacent natural structured habitat. Differences in abundance, as a metric of habitat preference, could be driven by life history features or biological factors such as prey choice or refuge. Sheepshead Archosargus probatocephalus and cunner Tautogolabrus adspersus were only observed in farm habitats, but are known to be associated with structure, and prey on bivalves and crustaceans usually closely associated with structure (Steimle \& Ogren 1982). In a comparison of aquaculture gear and created oyster reefs in Delaware's Inland Bays, Marenghi et al. (2010) noted that juvenile sheepshead were uniquely associated with farm cages that may provide enhanced foraging opportunities.

Availability of naturally structured estuarine habitat may be depressed relative to historic levels due to anthropogenic impacts. Oyster reefs are an important source of natural 3-dimensional habitat in estu-

Table 1. Summary of species observed in video footage. The number of raw observations per hour of viewable footage collected across sampling dates is shown. Species listed in bold are part of a commercial or recreational fishery in New Jersey. Classification of species by residency type is sourced from Breitburg (1998) and Coen et al. (1999)

\begin{tabular}{|c|c|c|c|c|c|}
\hline Common name & Species & Residency & Cage & Floating bag & Marsh \\
\hline Atlantic silverside & Menidia menidia & Transient & 310.67 & 3.14 & 23.55 \\
\hline Mummichog & Fundulus heteroclitus & Transient & 1.91 & 11.66 & 2.32 \\
\hline Feather blenny & Hypsoblennius hentz & Obligate & 0.99 & 2.75 & 0.87 \\
\hline Blue crab & Callinectes sapidus & Facultative & 0.53 & 1.24 & 1.64 \\
\hline Atlantic needlefish & Strongylura marina & Transient & 2.70 & 0 & 0 \\
\hline Grass shrimp & Palaemonetes spp. & Transient & 0.13 & 1.44 & 0.29 \\
\hline Naked goby & Gobiosoma bosci & Obligate & 0.26 & 0.85 & 0.39 \\
\hline Sheepshead & Archosargus probatocephalus & Facultative & 1.25 & 0.20 & 0 \\
\hline Silver perch & Bairdiella chrysoura & Transient & 1.25 & 0 & 0 \\
\hline Permit & Trachinotus falcatus & Transient & 0 & 0 & 1.06 \\
\hline Striped bass & Morone saxatilis & Transient & 0 & 0.98 & 0 \\
\hline Hermit crab & Pagurus spp. & Transient & 0.07 & 0.59 & 0 \\
\hline Cunner & Tautogolabrus adspersus & Transient & 0.40 & 0 & 0 \\
\hline Atlantic mud crab & Panopeus herbstii & Obligate & 0.07 & 0.07 & 0.10 \\
\hline Atlantic menhaden & Brevoortia tyrannus & Transient & 0 & 0 & 0.19 \\
\hline Summer flounder & Paralichthys dentatus & Transient & 0.07 & 0.07 & 0 \\
\hline Northern kingfish & Menticirrhus saxatilis & Transient & 0 & 0 & 0.10 \\
\hline Diamondback terrapin & Malaclemys terrapin & Transient & 0.07 & 0 & 0 \\
\hline American eel & Anguilla rostrata & Transient & 0 & 0.07 & 0 \\
\hline
\end{tabular}



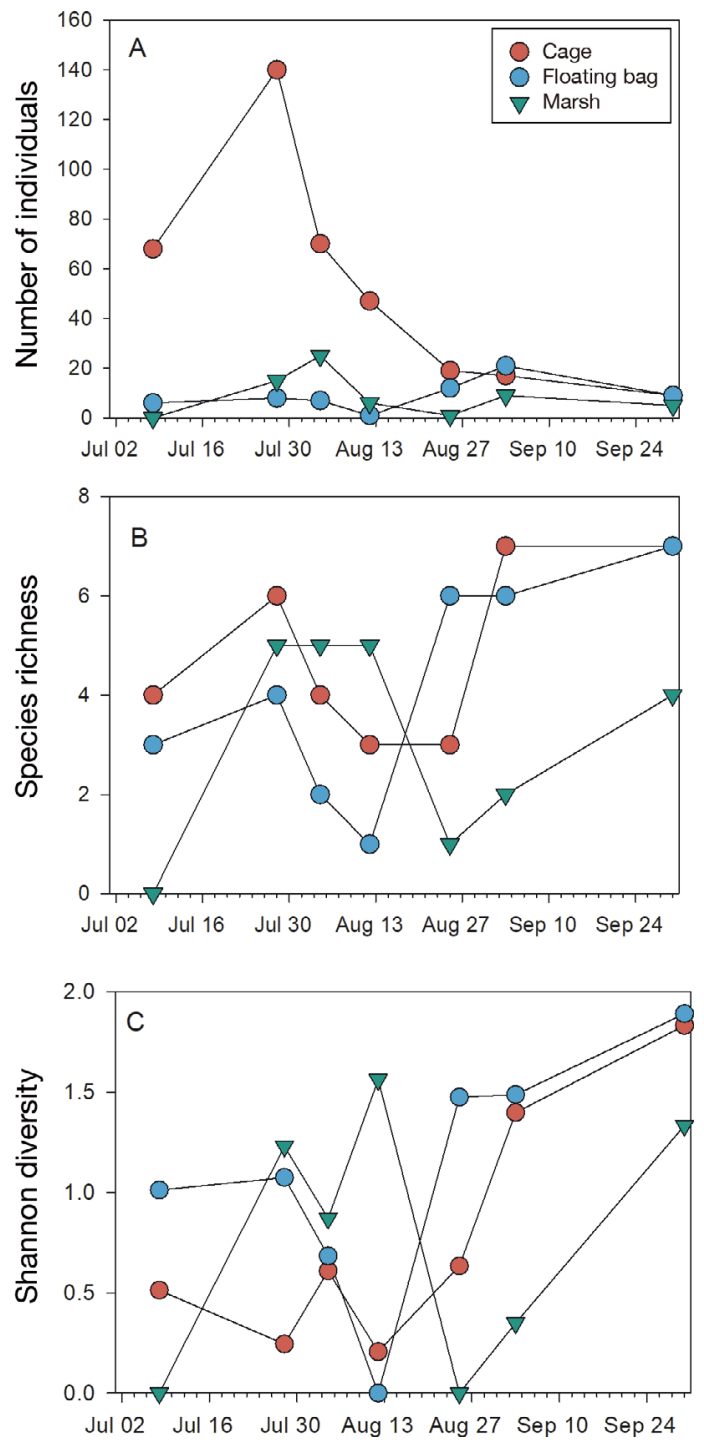

Fig. 2. (A) Total number of individuals (sum of MaxN across all species, where MaxN is defined as the maximum number of individuals of a given species present within each 80 min segment of video). (B) Species richness (total number of species observed). (C) Shannon diversity index for the 3 habitat types over the 7 dates during which video was collected $(n=21)$

aries, and have declined primarily due to historic overfishing (Beck et al. 2011). Oyster farms may provide similar habitat (Glenn 2016), and thus may be especially important sources of trophic resources in areas lacking natural reef habitat (Lefcheck et al. 2021). Several species classified as obligate reef residents were observed in this study in farm and natural marsh habitats, indicating that the services provided to the animals by these habitats may be comparable.

Young-of-the-year, juveniles, and adults of multiple species including blue crabs, Atlantic silversides
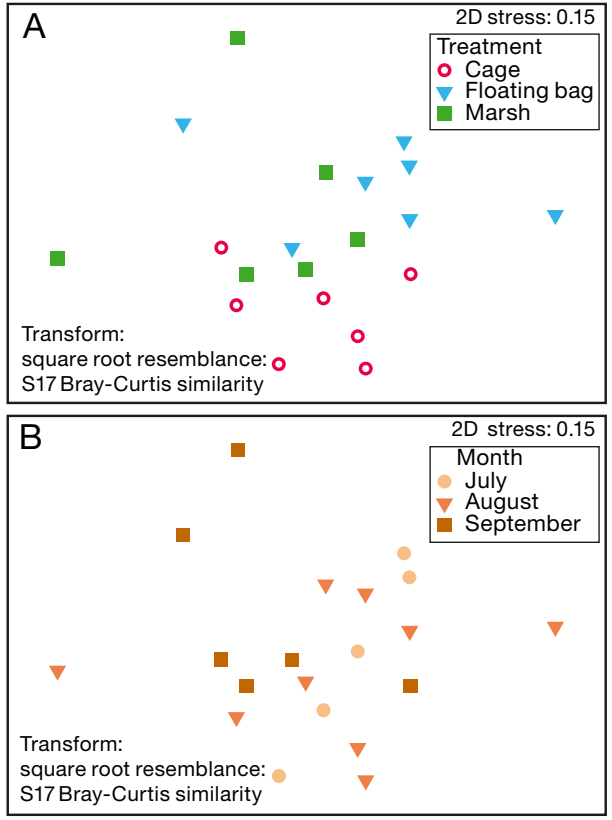

Fig. 3. Non-metric multidimensional scaling plots of nekton community based on MaxN calculated from each 80 min video for each species $(n=21)$, with overlays of $(A)$ habitat treatment type and (B) sampling month

Menidia menidia and grass shrimp (Palaemonetes spp.) were observed in farm habitats, suggesting that farms, like marshes, might enhance estuarine nursery function. One added benefit of using camera systems for data collection instead of traditional sampling techniques (e.g. lift nets, traps) is the ability to capture behavioral data. Interactive behaviors including predation, hunting, foraging, and shelter seeking were observed among several life history stages of animals. Although our data are insufficient for quantitative assessment of animal behaviors, an experiment addressing behavior would provide species-specific links to ecosystem services provided by oyster farms. Nonetheless, camera systems have limitations in their ability to capture data in habitats with obstructed views. Since all habitats sampled in this study were structured, species were likely present that went undocumented. In addition to increased sampling, multiple cameras simultaneously recording in a single habitat to reduce hidden views could help to reduce underestimation of species richness and other important community metrics.

Although the data and video footage captured during this study are limited by lack of replication across additional farms, they provide evidence of habitat provisioning for both finfish and invertebrates by intertidal oyster farms that could operate similarly to a naturally structured habitat. Globally, oyster aqua- 
culture accounts for one-third of all shellfish aquaculture production, and oyster farming has been increasing in Asia and Africa (Wijsman et al. 2019). As this sector continues to grow, it is important to understand the ecological role that oyster farms play in various nearshore coastal habitats around the world. Supporting management efforts by providing data about wildlife and aquaculture interactions is critical. The readily accessible methods employed here provide a relatively inexpensive way to document faunal utilization of various habitats, thus supporting expansion of this method to other regions of the world and cultivated species and gear types.

Acknowledgements. This research was primarily supported by the USDA NIFA Northeastern Regional Aquaculture Center. Additional support for D.M.M. was provided by the USDA National Institute of Food and Agriculture Hatch project accession number 1020831 through the New Jersey Agricultural Experiment Station, Hatch project NJ32140. We are grateful to our project partners at the NOAA Northeast Fisheries Science Center Milford Laboratory for sharing expertise: P. Clark, G. Phillips, and R. Mercaldo-Allen. We thank T. Lin and J. O'Brien for coding the video footage; J. Caracappa for help coding the results; and J. Morson, T. Grothues, and R. Hagan for help with species identification. We thank M. Zitter for providing access to the farm. We also thank A. Verkade for her comments on structured habitats used in the study. Finally, we thank 3 anonymous reviewers for their thoughtful comments that greatly improved the manuscript.

\section{LITERATURE CITED}

Beck MW, Brumbaugh RD, Airoldi L, Carranza A and others (2011) Oyster reefs at risk and recommendations for conservation, restoration, and management. BioScience 61: 107-116

Breitburg D (1998) Are three dimensional structure and healthy oyster populations the keys to an ecologically interesting and important fish community? In: Luckenbach M, Mann R, Wesson JA (eds) Oyster reef habitat restoration: a synopsis and synthesis of approaches. VIMS Press, Gloucester Point, VA, p 239-250

Campbell MD, Pollack AG, Gledgill CT, Switzer TS, DeVries DA (2015) Comparison of relative abundance indices calculated from two methods of generating video count data. Fish Res 170:125-133

Coen LD, Luckenbach MW, Breitberg DL (1999) The role of oyster reefs as essential fish habitat: a review of current knowledge and some new perspectives. In: Benaka LR (ed) Fish habitat: essential fish habitat and rehabilitation. American Fisheries Society, Bethesda, MD, p 438-454

DeAlteris J, Kilpatrick BD, Rheault RB (2004) A comparative evaluation of the habitat value of shellfish aquaculture gear, submerged aquatic vegetation and a non-vegetated seabed. J Shellfish Res 23:867-874
Erbland PJ, Ozbay G (2008) A comparison of the macrofaunal communities inhabiting a Crassostrea virginica oyster reef and oyster aquaculture gear in Indian River Bay, Delaware. J Shellfish Res 27:757-768

Ford SE (1997) History and present status of molluscan shellfisheries from Barnegat Bay to Delaware Bay. In: MacKenzie CL Jr, Burrell VG Jr, Rosenfield A, Hobart WL (eds) The history, present condition, and future of the mollusk fisheries of North and Central America and Europe, Vol 1. Atlantic and Gulf Coasts. NOAA Tech Rep NMFS 127, p 119-140

Friard O, Gamba M (2016) BORIS: a free, versatile opensource event-logging software for video/audio coding and live observations. Methods Ecol Evol 7:1325-1330

Glenn ME (2016) A comparison of macrofaunal and algal communities in oyster aquaculture gear, an eelgrass bed, oyster reef, and a mudflat in Great Bay, New Hampshire. MSc thesis, University of New Hampshire, Durham, NH

Holthe T (1975) A method for the calculation of ordinate values of the cumulative species-area curve. ICES J Mar Sci 36:183-184

Lefcheck J, Pfirrmann BW, Frodrie FJ, Grabowski JH, Hughes AR, Smyth AR (2021) Consumption rates vary based on the presence and type of oyster structure: a seasonal and latitudinal comparison. J Exp Mar Biol Ecol 536:151501

Marenghi F, Ozbay G, Erbland PJ, Rossi-Snook K (2010) A comparison of the habitat value of sub-tidal and floating oyster (Crassostrea virginica) aquaculture gear with a created reef in Delaware's Inland Bays, USA. Aquacult Int 18:69-81

Mercaldo-Allen R, Clark PA, Liu Y, Phillips G and others (2021) Exploring video and eDNA metabarcoding methods to assess oyster aquaculture cages as fish habitat. Aquacult Environ Interact 13:277-294

Muething KA, Tomas F, Waldbusser W, Dumbauld BR (2020) On the edge: assessing fish habitat use across the boundary between Pacific oyster aquaculture and eelgrass in Willapa Bay, Washington, USA. Aquacult Environ Interact 12:541-557

National Marine Fisheries Service (2020) Fisheries of the United States, 2018. US Department of Commerce, NOAA Current Fishery Statistics No. 2018

O'Beirn FX, Ross PG, Luckenbach MW (2004) Organisms associated with oysters cultured in floating systems in Virginia, USA. J Shellfish Res 23:825-829

Soniat TM, Finelli CM, Ruiz JT (2004) Vertical structure and predator refuge mediate oyster reef development and community dynamics. J Exp Mar Biol Ecol 310:163-182

Steimle FW Jr, Ogren L (1982) Food of fish collected on artificial reefs in the New York Bight and off Charleston, South Carolina. Mar Fish Rev 44:49-52

Wijsman JWM, Troost K, Fang J, Roncarati A (2019) Global production of marine bivalves. Trends and challenges. In: Smaal A, Ferreira J, Grant J, Petersen J, Strand $\varnothing$ (eds) Goods and services of marine bivalves. Springer, Cham, p 7-26

Wilcox RR (2017) Introduction to robust estimation and hypothesis testing, $4^{\text {th }}$ edn. Elsevier Academic Press, London

Willis TJ, Babcock RC (2000) A baited underwater video system for the determination of relative density of carnivorous reef fish. Mar Freshw Res 51:755-763
Editorial responsibility: Brett Dumbauld, Newport, Oregon, USA

Reviewed by: J. C Clements and 2 anonymous referees
Submitted: January 29, 2021

Accepted: May 17, 2021

Proofs received from author(s): July 7, 2021 